\title{
Sexual Function of Men Ages 40 to 79 Years: The Olmsted County Study of Urinary Symptoms and Health Status Among Men
}

\author{
Laurel A. Panser, MA, MS, 'Thomas Rhodes, MS, Cynthia J. Girman, DrPH, \\ Harry A. Guess, MD, PhD, ${ }^{\dagger \neq}$ Christopher G. Chute, MD, DrPH, ${ }^{`}$ Joseph E. Oesterling, MD, II \\ Michael M. Lieber, MD, " and Steven J. Jacobsen, $M D, P h D^{\ddagger}$
}

OBJECTIVES: Knowledge of male sexual function is somewhat limited because of a lack of current population-based data. This study provides information on sexual function and satisfaction in a population-based sample of men.

METHODS: Men aged 40 to 79 years $(n=2115)$ were selected randomly from the Olmsted County population for the baseline component of a prospective cohort study (the Olmsted County Study of Urinary Symptoms and Health Status Among Men) during 1989-1990. The men completed a self-administered questionnaire that included questions about sexual concerns, performance, satisfaction, drive, and erectile dysfunction.

RESULTS: For all five sexual parameters queried, the prevalence of problems and dysfunction increased with age. A comparison of men aged 70 to 79 years with men aged 40 to 49 years suggested that older men were more worried about sexual function $(46.6 \%$ vs $24.9 \%)$, had worsened performance compared with a year ago $(30.1 \%$ vs $10.4 \%)$, expressed extreme dissatisfaction with sexual performance $(10.7 \%$ vs $1.7 \%)$, had absent sexual drive $(25.9 \%$ vs $0.6 \%)$, and reported complete erectile dysfunction when sexually stimulated $(27.4 \%$ vs $0.3 \%)$. Logistic regression analyses suggested that sexual dissatisfaction was significantly associated with erectile dysfunction, decreased libido, and the interaction between erectile dysfunction and libido, but not age.

CONCLUSIONS: These population-based cross-sectional data corroborate the previously reported age-related decrease in sexual function. The age-related increase in dissatisfaction could, however, be accounted for primarily by the age-related increase in erectile dysfunction, decreased libido, and the

From the Sections of "Health Services Evaluation, \$clinical Fipidemiology, and SMedical Information Resources, Department of Health Sciences Research, and |Department of Urology, Mayo Clinic, Rechester, Minnesota; ${ }^{\dagger}$ Merck Research Laboratories, Blue Bell, Pennsylvania; and qThe Michigan Prostate Institure and the University of Michigan, Ann Arbor, Michigan.

This study was supported, in part, by grants from the US Public Health Service, National Institures of Health (AR 30582) and Merck Research laboratories, Bluc Bell, Pennsylvania.

Address correspondence and reprint requests to Dr. Steven J. Jacohsen, MI), PhD, Department of Health Sciences Research, Mayo Clinic, 200 First Street S.W., Rochester, MN 55905 . interaction between erectile dysfunction and decreased libido. J Am Geriatr Soc 43:1107-1111, 1995.

Sexual functioning is an important component in the qualSity of life of men. ${ }^{1-3}$ Current knowledge about male sexuality, however, is limited as a result of methodological shortcomings. Most studies of male sexuality have been conducted among convenience samples recruited through organizations such as universities, clubs and churches ${ }^{4-9}$ or clinical populations ${ }^{2.3,11)-17}$; only a few investigations have been population-based. ${ }^{18-20}$ In addition, with relatively few exceptions, ${ }^{4,5,20}$ most sample sizes have been small, leading to imprecise estimates of prevalence and limited statistical power to detect associations. The definitions of disorders have also been problematic. For example, some investigators have defined erectile dysfunction as no intercourse in the past year, ${ }^{13}$ which may measure the lack of a partner instead of organic or psychogenic impairment. ${ }^{3}$ Simultaneous measurement of several concepts in one item makes comparisons across studies difficult. ${ }^{21}$ Furthermore, because recent sex research initiatives have been abandoned, ' future data will be limited.

As part of a population-based study of the natural history of benign prostatic hyperplasia and lower urinary tract symptoms, five dimensions of male sexuality were measured through a self-administered questionnaire. These crosssectional data provide estimates of the prevalence of erectile dysfunction, decreased libido, sexual worry, and changes in sexual performance and sexual satisfaction among white men aged $40-79$ years.

\section{MATERIALS AND METHODS}

\section{Setting and Subjects}

The Olmsted County Study of Urinary Symptoms and Health Status Among Men is a longitudinal study mounted to describe the natural history of lower urinary tract symptoms and benign prostatic hyperplasia in the population. ${ }^{22,2.3}$ The study protocol was approved by Mayo Clinic's Institutional Review Board. The unique resources of the Rochester Epidemiology Project ${ }^{24}$ were used to enumerate the population of Olmsted County. Comparisons with census data suggest this provided a $96 \%$ enumeration of the County population. From a sampling frame of all males 40 to 79 years of age, 
5135 residents were randomly selected within each 5-year age- and geographic-specific stratum (Rochester city vs the balance of Olmsted County) at a $14 \%$ sampling fraction. The medical records of potential subjects were reviewed for predefined exclusion criteria, including a history of known voiding dysfunction, such as prostate cancer or prostate surgery, apart from benign prostatic hyperplasia. Letters of invitation were mailed to eligible men. From December 1989 through March 1990, field research assistants visited subjects at home to collect baseline data. Face-to-face interviews elicited current medications and family history of urologic disease. Following this, subjects completed a previously validated, selfadministered questionnaire $e^{2.5}$ that assessed urinary symptoms, general health, and five indicators of sexual functioning (only the satisfaction item was included in the validation investigation). Of the 5135 men selected, 1265 did not meet eligibility criteria, 20 could not be traced before enrollment, 1735 refused participation, and 2115 participated fully, yielding a response rate of $55 \% .{ }^{26}$

The questionnaire elicited information about five sexual parameters. With reference to the past month, subjects were asked to rate three measures of sexual function: (1) worry or concern about sexual functioning (6-point scale from $1=$ not at all to $6=$ extremely); (2) ability to have erections when sexually stimulated (6-point scale from $1=$ all the time to $6=$ none of the time); and (3) frequency of sexual drive (including wanting to masturbate or have intercourse, planning to have sex, or feeling frustrated due to a lack of sex) (8-point scale from $1=$ not at all to $8=$ more than once a day). Subjects were also asked their level of satisfaction with sexual activity or lack of sexual activity on an 11-point scale $(0=$ extremely dissatisfied, $10=$ very satisfied). Finally, men indicated whether their sexual performance during the past year had improved, become worse, or stayed the same on a 7-point, ordinal scale.

\section{Analysis}

Spearman correlation coefficients were used to estimate the bivariate associations between age (continuous) and each sexual parameter. Multiple logistic regression models were constructed with sexual dissatisfaction as the dependent variable. For purposes of analysis, dissatisfaction included the four lowest responses from 11 possibilities; erectile dysfunction was defined as erections little or none of the time when stimulated; sexual worry included some worry or more; decreased libido included sexual drive two or three times per month or less; and decreased sexual performance included somewhat or much worse status compared with a year ago. Models constructed included age, erectile dysfunction, and decreased libido. In addition, variables for second-order interaction terms were included.

\section{RESULTS}

Among the 2115 participants, $97.6 \%$ had ever been married, almost $90 \%$ had a high school education or greater, $78.3 \%$ had a gross family income of $\$ 25,000$ or more, and $67 \%$ of the men were less than 60 years of age. Most of the 2115 study cohort members provided complete sexuality data; however, $122(5.8 \%)$ men did not answer one or more of the five sexuality questions. Compared with men who provided all sexuality data, men who did not were older, less educated, less likely to have been currently married, and had lower annual household incomes.
Sexual satisfaction and worry varied with age among the subjects. Overall, $13 \%$ of men were very satisfied with their level of sexual activity. The proportion of subjects expressing extreme dissatisfaction, however, increased with each successively older age group; $1.7 \%$ of men aged 40 to 49 years were extremely dissatisfied in contrast with $10.7 \%$ of men aged 70 years or older. Generally, sexual satisfaction decreased with increasing age in these cross-sectional data $\left(r_{\mathrm{S}}=-.12, P<\right.$ $.0001)$. More than half of men of all ages were not at all worried or concerned about their sexual functioning over the past month, but the proportion reporting worry increased with advancing age. Only $25 \%$ of men aged 40 to 49 years reported at least some degree of worry compared with $45 \%$ of men aged 60 or more years. The cross-sectional correlation between age and worry was $-0.19(P<.0001)$.

Similarly, self-rated sexual performance and drive varied across age groups. Among all age groups, $81.5 \%$ reported a static or improved sexual performance compared with a year ago. The proportion of subjects who reported a worsened performance increased with age from $10.4 \%$ of men aged 40 to 49 years to $30.1 \%$ among men 70 years of age or older. This is partly explained by the smaller percentage of older men reporting static performance; among men aged 40 to 49 years, $79.8 \%$ reported static performance compared with $69 \%$ of men aged 60 years or greater. Generally, sexual performance decreased with increasing age in these crosssectional data $\left(r_{\mathrm{s}}=-.24, P<.001\right)$. Overall, $93.8 \%$ of men reported at least some sexual drive during the past month. The percentage of men without sexual drive increased with increasing age $\left(r_{\mathrm{S}}=-.53, P<.001\right)$; only $0.6 \%$ of subjects aged 40 to 49 years reported no sex drive compared with $26 \%$ of men 70 years of age or older. Moreover, the percentage of men reporting sexual drive more frequently than one time per week was lower for each successively older age decade; among men aged 40 to 49 years, $77 \%$ experienced sexual drive more than one time per week in contrast with $10.4 \%$ of subjects aged 70 years or greater.

Overall, $93.6 \%$ of the men aged 40 to 79 years reported at least some erectile function when sexually stimulated during the past month. However, the percentage decreased with increasing age $\left(r_{S}=-.48, P<.001\right)$, with $77 \%$ of men aged 40 to 49 years able to have erections all of the time, compared with $18 \%$ of men aged 70 years or more. Conversely, the percentage of subjects who were able to have erections a little or none of the time increased with age; fewer than $1 \%$ of men aged 40 to 49 years were able to have erections none of the time in comparison to more than one-quarter of men 70 years of age or older.

The five measures of sexual function were related to one another. Spearman correlation coefficients for the associations between these variables (Table 1) ranged in magnitude from 0.06 to 0.58 , but the correlations were usually higher for older men (age 60-79) compared with younger men (age 40-59). The cross-sectional association between dissatisfaction and other parameters is presented in Table 2. Sexual dissatisfaction was significantly associated with increasing age, erectile dysfunction, worry about sexual function, decreased libido, and decreased sexual performance. The logistic regression analyses that simultaneously adjusted for age and sexual function parameters suggested that sexual dissatisfaction was not significantly associated with age; the significant predictors were erectile dysfunction, libido, and an interaction term for libido and erectile dysfunction (Figure 1). 
Table 1. Cross-sectional Association Between Five Sexuality Variables Among White Men, by Age*

\begin{tabular}{|c|c|c|c|c|c|c|c|c|c|c|}
\hline & \multicolumn{5}{|c|}{ Age 40-59 Years } & \multicolumn{5}{|c|}{ Age $60-79$ Years } \\
\hline & $\begin{array}{c}\text { Sexual } \\
\text { Satisfaction }\end{array}$ & $\begin{array}{c}\text { Sexual } \\
\text { Drive }\end{array}$ & $\begin{array}{l}\text { Erectile } \\
\text { Function }\end{array}$ & $\begin{array}{c}\text { Sexual } \\
\text { Performance }\end{array}$ & $\begin{array}{l}\text { Worry } \\
\text { About } \\
\text { Sex }\end{array}$ & $\begin{array}{c}\text { Sexual } \\
\text { Satisfaction }\end{array}$ & $\begin{array}{c}\text { Sexual } \\
\text { Drive }\end{array}$ & $\begin{array}{l}\text { Erectile } \\
\text { Function }\end{array}$ & $\begin{array}{c}\text { Sexual } \\
\text { Performance }\end{array}$ & $\begin{array}{l}\text { Worry } \\
\text { About } \\
\text { Sex }\end{array}$ \\
\hline Sexual drive & 0.18 & 1.0 & & & & 0.25 & 1.0 & & & \\
\hline Erectile function & -0.33 & -0.24 & 1.0 & & & -0.47 & -0.58 & 1.0 & & \\
\hline Sexual performance & 0.32 & 0.23 & -0.32 & 1.0 & 0.0 & 0.44 & 0.19 & -0.35 & 1.0 & \\
\hline Worry about sex & -0.40 & -0.21 & 0.45 & -0.43 & 1.0 & -0.52 & -0.06 & 0.33 & -0.50 & 1.0 \\
\hline
\end{tabular}

- Spearman correlation coefficients. All $P$ values were $<.0001$ for the associations between pairs of sexuality variables within 20 -year age groups (except for the correlation between worry and libido among men aged 60 to 79 years $(P=.15))$.

Table 2. Factors Associated with Sexual Dissatisfaction* Among White Men Aged 40-79 Years

\begin{tabular}{|c|c|c|c|c|}
\hline \multirow[b]{2}{*}{ Characteristic } & \multirow[b]{2}{*}{$\begin{array}{c}\text { Dissatisfied } \\
\text { nt }\end{array}$} & \multirow[b]{2}{*}{$\begin{array}{c}\text { Satisfied } \\
\text { n† }\end{array}$} & \multicolumn{2}{|c|}{ Crude } \\
\hline & & & Odds Ratio & $\begin{array}{l}\text { 95\% Confidence } \\
\text { Interval }\end{array}$ \\
\hline \multicolumn{5}{|l|}{ Age (years) } \\
\hline $40-49$ & 100 & 688 & 1.00 & \\
\hline $50-59$ & 83 & 514 & 1.11 & $0.81,1.52$ \\
\hline $60-69$ & 85 & 333 & 1.76 & $1.28,2.41$ \\
\hline $70-79$ & 59 & 175 & 2.32 & $1.62,3.33$ \\
\hline \multicolumn{5}{|l|}{ Erectile dysfunction } \\
\hline Absent & 201 & 1575 & 1.00 & \\
\hline Present & 117 & 116 & 7.90 & $5.88,10.62$ \\
\hline \multicolumn{5}{|l|}{ Sexual worry } \\
\hline Absent & 158 & 1508 & 1.00 & \\
\hline Present & 161 & 189 & 8.13 & $6.23,10.61$ \\
\hline \multicolumn{5}{|l|}{ Libido } \\
\hline Normal or high & 185 & 1321 & 1.00 & \\
\hline Decreased & 135 & 372 & 2.59 & $2.02,3.33$ \\
\hline \multicolumn{5}{|l|}{ Sexual performance } \\
\hline Normal or better & 214 & 1641 & 1.00 & \\
\hline Decreased & 105 & 48 & 16.77 & $11.59,24.28$ \\
\hline
\end{tabular}

- Satisfaction levels 0 through 3.

† Sample size.

The joint effect of libido and erectile dysfunction was less than multiplicative; nonetheless, men who had both normal to high libido and erectile dysfunction seemed to be at especially high risk of dissatisfaction. Because age was no longer a significant predictor of satisfaction after controlling for these factors, these cross-sectional data suggest that age per se may not be as important in the prediction of sexual dissatisfaction as sexual attributes that are related to age.

\section{DISCUSSION}

Sexual function is an important component of the quality of life of men. These sexual function data rectify some of the deficiencies in the male sexuality literature. The generalizability of clinic-derived data is questionable because patients tend to overrepresent individuals with disorders known to cause erectile dysfunction (such as diabetes mellitus and atherosclerosis), ${ }^{3}$ men with multiple disorders, or men with rare etiologies leading to erectile dysfunction. Additionally, data derived from volunteers may overrepresent disinhibited $^{11}$ or sexually aggressive ${ }^{9}$ individuals. The Olmsted
County study was language inclusive for heterosexual and homosexual men, included mutually exclusive and exhaustive response options, and all questions (except the satisfaction item) referred to only one construct and a specified time frame. The study included 707 men aged 60 years or older, making this one of the largest contemporary studies addressing sexual function among older U.S. males.

The Olmsted County study had several limitations. A $55 \%$ response rate was realized at baseline. However, this may not create problems because (1) potential subjects had no reason to suspect sex questions would be asked, and (2) responders and nonresponders were comparable at baseline in terms of health care-seeking behavior, nonurologic morbidities, and home location within the county. ${ }^{27}$ Nevertheless, responders may have overrepresented men with some urologic diagnoses. Additionally, no data were collected regarding sexual activity or earlier life sexual interest (which may affect later interest in sex), ${ }^{13}$ sexual orientation, attributes of the sex partner, or relationship dynamics. Further, some men may have understated their sexual problems. ${ }^{7}$ It is 


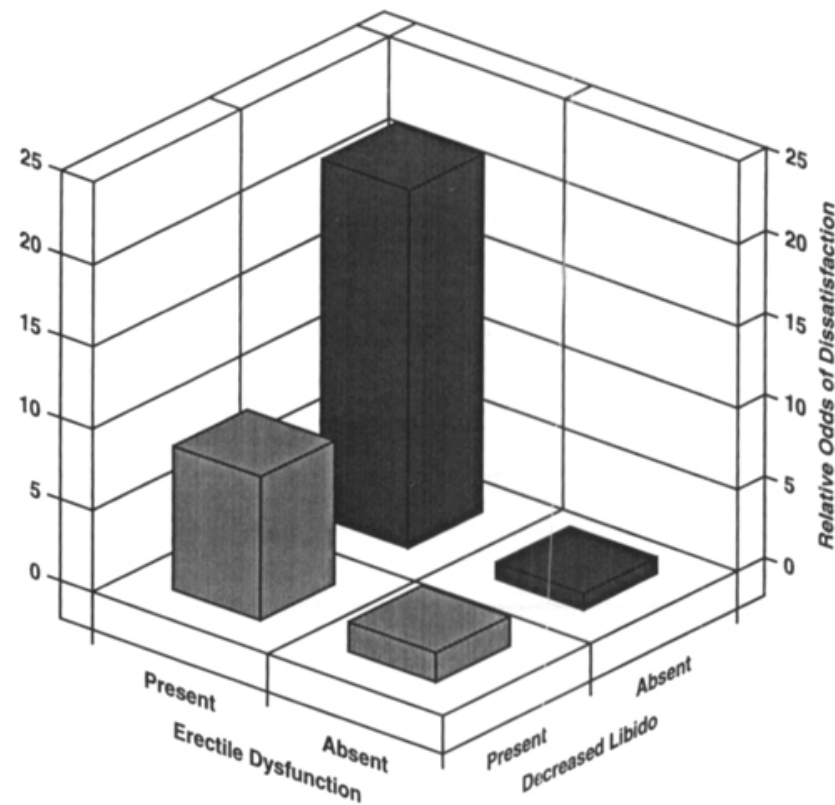

Figure 1. The age-adjusted relative odds of sexual dissatisfaction by level of erectile dysfunction and libido. Erectile dysfunction (present): Erections little or none of the time during the past month when stimulated. Decreased libido (present): Sexual drive two or three times per month or less.

also not possible at baseline to distinguish lifelong (primary) from acquired (secondary) erectile dysfunction. Finally, subjects were white, midwestern men from a relatively small community who were known not to have voiding dysfunction and may not represent all North American men.

These cross-sectional prevalence data suggest sexual drive, performance, satisfaction, worry-free status, and erectile function may decrease with advancing age among middleaged and older men. In general, the literature is consistent with those findings. $4,6-7,9,15-17,19-20,28-31$ The literature regarding the prevalence of erectile dysfunction, however, is difficult to interpret because definitions of dysfunction have varied. ${ }^{20}$ Some studies simultaneously measured erectile function with another sexual parameter ${ }^{13}$ and some reports equate any instance of intercourse with intact erectile function, ${ }^{11,13}$ which ignores the significant percentage of men without sexual partners. ${ }^{3}$ Nonetheless, virtually all crosssectional studies $4,7,15-16,19-20,29$ suggest decreasing erectile function with advancing age. However, longitudinal studies are needed to provide a better understanding of these suggested effects of aging. ${ }^{29,32}$

In the current study, sexual satisfaction decreased with increasing age. As has been found in other cross-sectional studies of middle aged and older men, sexual satisfaction ${ }^{29}$ and enjoyment ${ }^{30}$ decreased with increasing age. However, dissatisfaction was not predicted by age, per se, but rather by sexual attributes (erectile function and libido) that were themselves age-related. Nonetheless, more men were satisfied than dissatisfied at every age. Overall, these cross-sectional data suggest that aging per se may not lead to dissatisfaction. Rather, dissatisfaction may be due to age-related declines in physiologic function and the potential failure to compensate psychologically for that loss.

\section{ACKNOWLEDGMENTS}

The authors thank members of the Mayo Clinic BPH study staff, especially Rebecca Nelson, Karen Hanson, Luanne Schmidt, Deitra Pickett, Charles Wilson, Roger Mueller, and Priscilla Van Grevenhof. The authors also sincerely thank Hsing-Yi Chang for statistical analysis, Daniel E. Rohe, PhD, for interpretive consultation and Sondra Buehler and Yvonne Weeldreyer for assistance with manuscript preparation.

\section{REFERENCES}

1. Gardner W. Wilcox BL. Political intervention in scientific peer review: Research on adolescent sexual behavior. Am Psychol 1993:48:972-983.

2. Slag MF, Morley JE, Elson MK et al. Impotence in medical clinic outpatients. JAMA 1983;249:1736-1740.

3. Cogen $R$, Steinman W. Sexual function and practice in elderly men of lower socioeconomic status. J Fam Pract 1990;31:162-166.

4. Kinsey AC, Pomeroy WB, Martin CE. Sexual Behavior in the Human Male. Philadelphia: WB Saunders Company, 1948.

5. Gebhard PH, Johnson AB. The Kinsey Data: Marginal Tabulations of the 1938-1963 Interviews Conducted by the Institute for Sex Research. Philadelphia: WB Saunders Company, 1979.

6. Newman (; Nichols C.R. Sexual activities and attitudes in older persons. JAMA 1960;173:33-35.

7. Frank E, Anderson C, Rubinstein D. Frequency of sexual dysfunction in "normal" couples. N Engl J Med 1978;299:111-115.

8. Spector KR, Boyle $M$. The prevalence and perceived aetiology of male sexual problems in a non-clinical sample. Br J Med Psychol 1986;59:351-358.

9. Freeman JT. Sexual capacities in the aging male. Ceriatrics 1961;16:37-43.

10. Masters WH, Johnson VE. Human Sexual Inadequacy. Boston, MA: Little Brown and Company, 1970.

11. Pearlman CK. Frequency of intercourse in males at different ages. Medical Aspects of Human Sexuality 1972;6:92-113.

12. Golombok S, Rust J, Pickard C. Sexual problems encountered in general practice. Br J Sex Med 1984;1 1:210-212.

13. Finkle AL, Moyers TG, Tobenkin MI, Karg SJ. Sexual potency in aging males: 1. Frequency of coitus among clinic patients. JAMA 1959:170:13911393.

14. Moore JT, Goldstein Y. Sexual problems among family medicine patients. I Fam Pract 1980; 10:24.3-247.

15. Mulligan T, Moss CR. Sexuality and aging in male veterans: $A$ crosssectional study of interest, ability, and activity. Arch Sex Behav 1991;20:1725.

16. Mulligan T, Retchin SM, Chinchilli VM, Bettinger CB. The role of aging and chronic disease in sexual dysfunction. J Am Geriatr Soc 1988;36:520-524.

17. Kaiser FF, Viosca SP, Morley JF. ct al. Impotence and aging: Clinical and hormonal factors. J Am Cieriatr $S(x)$ 1988;36:511-519.

18. Palmore E. Appendix A. Design of the Adaptation Study. In: Palmore E, ed. Normal Aging II. Durham NC: Duke University Press, 1974, pp 291-296.

19. Diokno AC, Brown MB, Herzog AR. Sexual function in the elderly. Arch Intern Med 1990; 150:197-200.

20. Feldman HA, Goldstein I, Hatzichristou DG et al. Impotence and its medical and psychosocial correlates: Results of the Massachusetts male aging study. J Urol 1994;151:54-61.

21. Spector IP, Carey MP. Incidence and prevalence of the sexual dysfunctions: A critical review of the empirical literature. Arch Sex Behav 1990;19:389408.

22. Chute C., Panser L.A, Girman CJ et al. The prevalence of prostatism: A population-based survey of urinary symptoms. J Urol 1993;150:85-89.

23. Jacobsen SJ, Guess HA, Panser I.A et al. A population-based study of health care-seeking behavior for treatment of urinary symptoms: The Olmsted County Study of Urinary Symptoms and Health Status Among Men. Arch Fam Med 1993;2:729-735.

24. Kurland LT, Molgaard CA. The patient record in epidemiology. Sci Am 1981;245:54-63.

25. Fpstein RS, Deverka PA, Chute CG et al. Validation of a new quality of life questionnaire for benign prostatic hyperplasia. J Clin Epidemiol 1992;45:1431-144.5.

26. Panser LA. Chute CG, Girman CJ et al. Effect of several recruitment strategies on response rates at baseline in a prospective cohort investigation: The Olmsted County Study of Urinary Symptoms and Health Status Among Men. Ann Epidemiol 1994;4:321-326. 
27. Panser LA, Chute C $C$, (iuess HA et al. The natural history of prostatism: The effects of non-response bias. Int J Epidemiol 1994;23:1198-1205.

28. Pfeiffer F, Verwoerde A, Davis GC.. Sexual behavior in middle life. Am J Psy chiatry 1972;128:1262-1267.

29. Schiavi RC:, Schreiner-Fngel $P$, Mandeli J et al. Healthy aging and male sexual function. Am J Psychiatry 1990;147:766-771.
30. Pteiffer F., Davis CiC.. Determinants of sexual behavior in middle and old age. I Am Ceriatr Soc 1972;20:151-158.

31. Verwoerde A, Pfeiffer E, Wang HS. Sexual behavior in senescence. II. Patterns of sexual activity and interest. Cieriatrics 1969;24:137-154.

32. George I.K, Weiler S]. Sexuality in middle and late life: The effects of age cohort and gender. Arch Gen Psychiatry 1981;38:919-923. 